\title{
Design and Compare of Two Coplanar Fed Ultra Wideband Antenna
}

\author{
Rahul Kumar Gupta \\ Department of Electronics \&Communication \\ Engineering \\ Sushila Devi Bansal College of Technology, Indore, \\ India
}

\begin{abstract}
In this paper, design and analysis of two compact coplanar waveguide (CPW) fed ultra wideband (UWB) slot antenna is presented. The proposed antenna consists of a rectangular slot on a ground plane and a triangular patch and another semicircular patch at the interior portion of the feed that acts as tuning stub of the antenna. The return loss of the developed antenna are measured and compared, which shows that measured result is in good agreement with simulation. It is also seen that the proposed antenna has relatively stable Omni directional radiation pattern in the $\mathrm{H}$ plane and bidirectional radiation pattern in the $\mathrm{E}$ plane over the frequency range of $3.91 \mathrm{GHz}$ to $10.6 \mathrm{GHz}$
\end{abstract}

\section{Keywords}

Slot Antenna, Coplanar Waveguide, Return Loss, Ultra Wideband

\section{INTRODUCTION}

The mild and rapid development of wireless industry in the recent years, there is a need of minimal compact, low profile microstrip antenna with high gain and bandwidth. The wireless industries are engaged in development of UWB antennas with characteristics of high data rate transfer in interference free environment, to satisfy the need of consumer electronics. As a key component of UWB communication system, the study of UWB antennas electrical characteristics for indoor and outdoor applications is reported by many researchers. Federal Communications Commission (FCC) has approved spectrum from $3.1 \mathrm{GHz}-10.6 \mathrm{GHz}$ of bandwidth of $7.5 \mathrm{GHz}$ for UWB communication system. Planar antennas are studied for wide band operation with various shaped tuning stub like ellipse, cone, semi-circular, $\mathrm{U}$ and rectangular round cornered. All these articles have well reported the advantages of planar geometry such as wide impedance bandwidth and Omni-directional radiation pattern.

In this paper, a triangular patch is frequently used in microstrip antennas, which provides radiation characteristics similar to rectangular patch with smaller area. The proposed antenna in this paper is designed with a compact rectangular slot and a triangular feed structure at the interior portion of the feed. Another paper, a novel CPW-fed UWB rectangular aperture antenna with simple geometry is presented. The compact rectangular aperture antenna is fed by a $50 \Omega \mathrm{CPW}$ transmission line, where the end is terminated by a semicircle tuning stub. The whole feeding structure looks like a mushroom shape, which has a simpler geometry structure and fewer parameters. Details of the antenna design are discussed, FR4 substrate with dielectric constant of 4.3.

\author{
Pramendra Tilanthe, Ph.D \\ Department of Electronics \&Communication \\ Engineering \\ Sushila Devi Bansal College of Technology, Indore, \\ India
}

and experimental results of the proposed antenna are presented and analyzed.

\section{SLOT ANTENNA}

A Slot antenna is typically used at frequency between 300 $\mathrm{MHz}$ and $24 \mathrm{GHz}$. The slot antenna is popular because they can be cut out of whatever surface they are to be mounted on and have radiation pattern that are roughly Omni-directional. The polarization of slot antenna is linear. The slot size, shape and what is behind it offer design variables that can be used to tune performance.

\subsection{Antenna Design-I}

The geometry of triangular patch CPW-Fed slot antenna Design-I is illustrated in figure 1.The geometry of this antenna was modified and its dimension optimizes using HFSS ver.13.0 and compared with original antenna. The antenna has a compact slot size of $15 \times 12 \mathrm{~mm}^{2}$, fabricated on FR4 substrate with dielectric constant of 4.4 , thickness of $1.6 \mathrm{~mm}$. The other dimensions are mention in table 1.

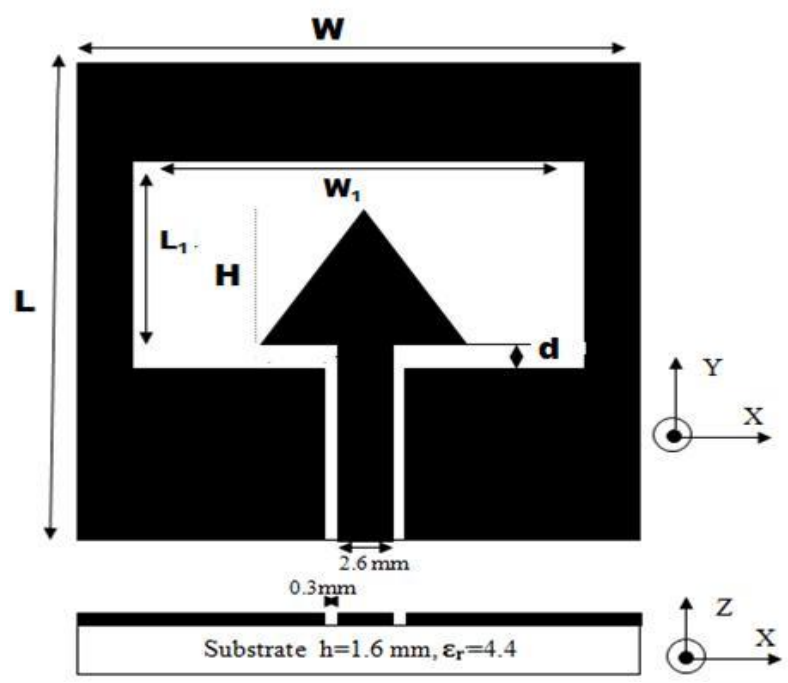

Figure 1. Geometry of CPW-Fed slot antenna Design-I

\subsection{Antenna Design-II}

The geometry of semi-circular patch CPW-Fed slot antenna Design-II is illustrated in figure 2 . The geometry of this antenna was modified and its dimension optimizes using HFSS ver.13.0 and compared with original antenna. The antenna has a compact slot size of $22 \times 13 \mathrm{~mm}^{2}$, fabricated on 


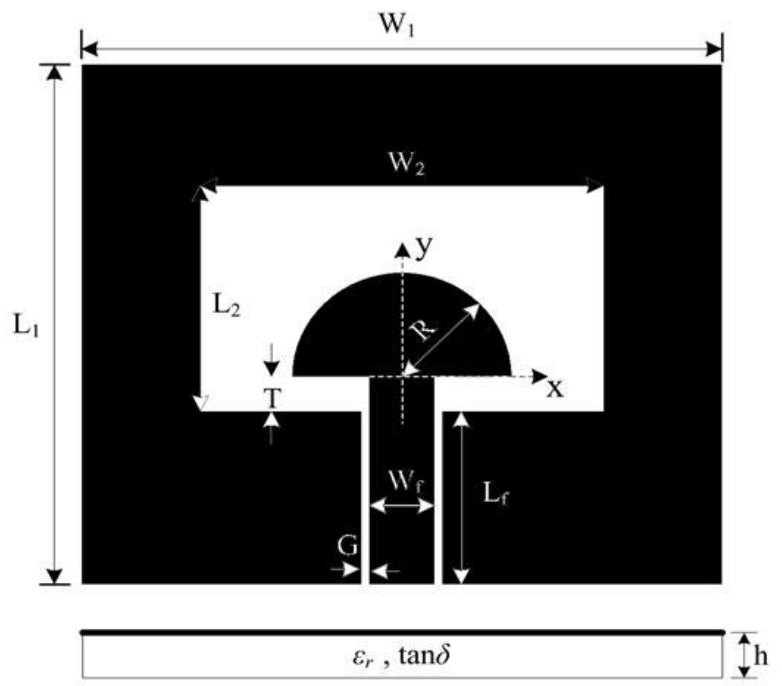

Figure 2. Geometry of CPW-Fed slot antenna Design-II

Table 1.Geometry of Antenna-I

\begin{tabular}{|c|c|c|}
\hline Description & $\begin{array}{c}\text { Parameter of } \\
\text { Antenna-I } \\
(\mathbf{m m})\end{array}$ & $\begin{array}{c}\text { Parameter of } \\
\text { Antenna-II } \\
(\mathbf{m m})\end{array}$ \\
\hline Length of the antenna & $\mathrm{L}=21$ & $\mathrm{~L}_{1}=29$ \\
\hline Width of the antenna & $\mathrm{W}=20$ & $\mathrm{~W}_{1}=34$ \\
\hline Length of the slot & $\mathrm{L}_{1}=12$ & $\mathrm{~L}_{2}=22$ \\
\hline Width of the slot & $\mathrm{W}_{1}=15$ & $\mathrm{~W}_{2}=13$ \\
\hline Feed gap distance & $\mathrm{d}=1.4$ & $\mathrm{~T}=2$ \\
\hline Height of the patch & $\mathrm{H}=7$ & $\mathrm{R}=6$ \\
\hline Height of feed & 5.6 & 12 \\
\hline Thickness of substrate & $\mathrm{h}=1.6$ & $\mathrm{~h}=1.5$ \\
\hline
\end{tabular}

\section{IMPLEMENTED DESIGN \& RESULT 3.1 Antenna Design-I}

The triangular patch antenna is modified by cutting rectangular slot vertically of dimension $1.5 \mathrm{~mm} \times 6.8 \mathrm{~mm}$ on both the side illustrated in Figure 3. It gives the bandwidth of $8.8 \mathrm{GHz}$ whose range is $3.91 \mathrm{GHz}-12.85 \mathrm{GHz}$. The higher cut off frequency is more than UWB.

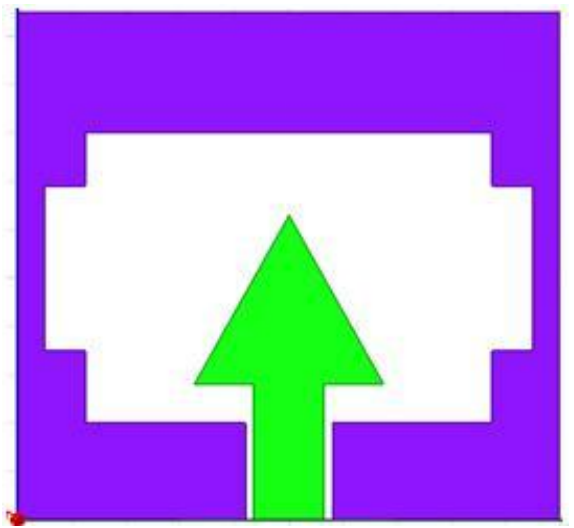

Figure 3. Geometry of Modified CPW-Fed Rectangular slot antenna Design-I

Here, S-Parameter of antenna design-I is shown in figure 4 dashed line show the S-Parameter of original antenna design-I and continuous line shows the modified antenna design-I. The original antenna-I is non radiating at $5.9-7.8 \mathrm{GHz}$ which is removed by modification. Table 2 shows the bandwidth comparison between antenna-I and Modified antenna-II.

Table 2. Comparison between Antenna-I and Modified Antenna-I

\begin{tabular}{|c|c|c|}
\hline Description & Range of Frequency & Bandwidth \\
\hline Antenna-I & $4.1 \mathrm{GHz}-11.9 \mathrm{GHz}$ & 7.8 \\
\hline $\begin{array}{l}\text { Modified } \\
\text { Antenna-I }\end{array}$ & $3.91 \mathrm{GHz}-12.85 \mathrm{GHz}$ & 8.94 \\
\hline
\end{tabular}

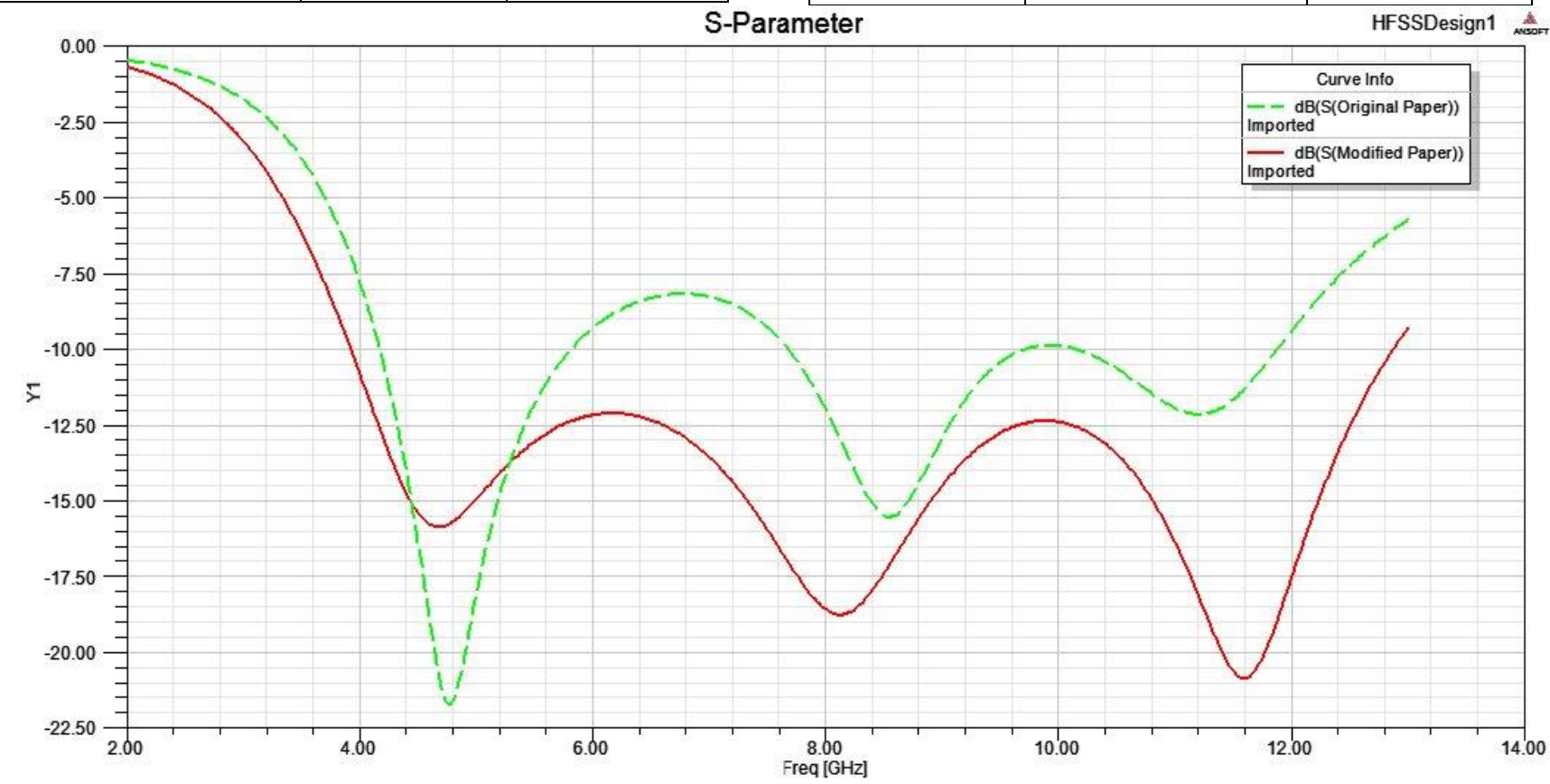

Figure 4. Simulated S-Parameter of Modified CPW-Fed Rectangular slot antenna Design-I 


\subsection{Radiation Pattern}

The simulated radiation pattern of E-Plane and H-Plane are obtained at $5 \mathrm{GHz}, 7.5 \mathrm{GHz}$ and $10 \mathrm{GHz}$ as shown in figure 5 . It is noticed that in E-Plane the radiation pattern is bidirectional. As the frequency increases gain of the antenna increases but its distracted cause of cutting rectangular slot vertically.

\section{E-Plane}
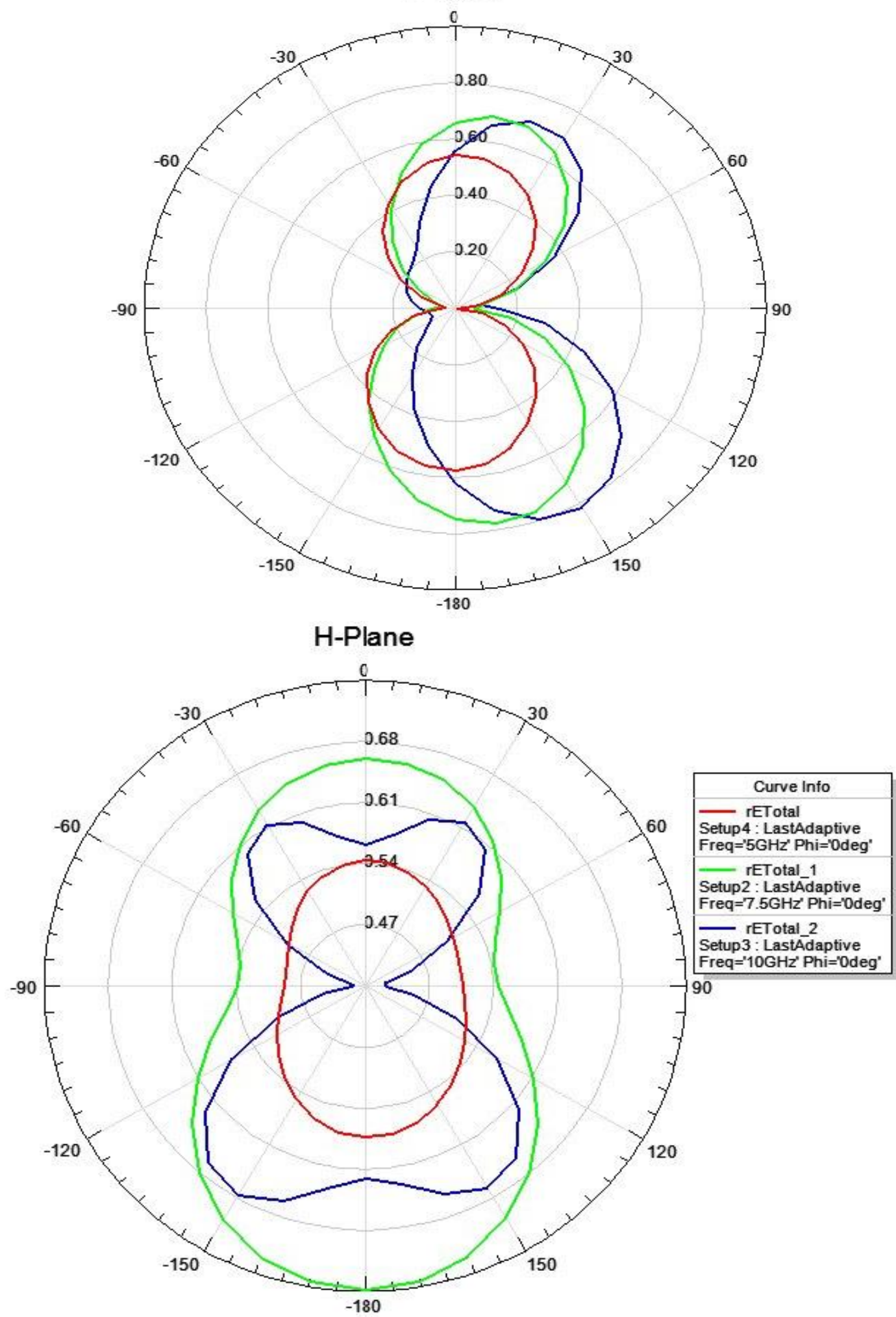

Figure 5. Radiation pattern of Modified CPW-Fed Rectangular slot antenna Design-I at $5 \mathrm{GHz}, 7.5 \mathrm{GHz}$ and $10 \mathrm{GHz}$ a) E-Plane (yz-plane) b) H-Plane (xz-plane) 


\subsection{Antenna Design-II}

The Semi-circular patch CPW-Fed antenna is modified by shifting rectangular slot by $1.5 \mathrm{~mm}$ right side of the patch and changing the size of width slot $\mathrm{L}_{2}$ from $13 \mathrm{~mm}$ to $15 \mathrm{~mm}$. It gives the bandwidth of $8.05 \mathrm{GHz}$ whose range is $3.33 \mathrm{GHz}-$ 11.38GHz.This result is analyse in table 3 .and figure 7.There is a non radiating band with original antenna design-II freqency range $4.4 \mathrm{GHz}$ to $5.9 \mathrm{GHz}$.

Table 3. Comparison between Antenna-II and Modified Antenna-II

\begin{tabular}{|c|c|c|}
\hline Description & Range of Frequency & Bandwidth \\
\hline Antenna-II & $3.3 \mathrm{GHz}-11.33 \mathrm{GHz}$ & 8.03 \\
\hline $\begin{array}{c}\text { Modified } \\
\text { Antenna-II }\end{array}$ & $3.33 \mathrm{GHz}-11.38 \mathrm{GHz}$ & 8.05 \\
\hline
\end{tabular}

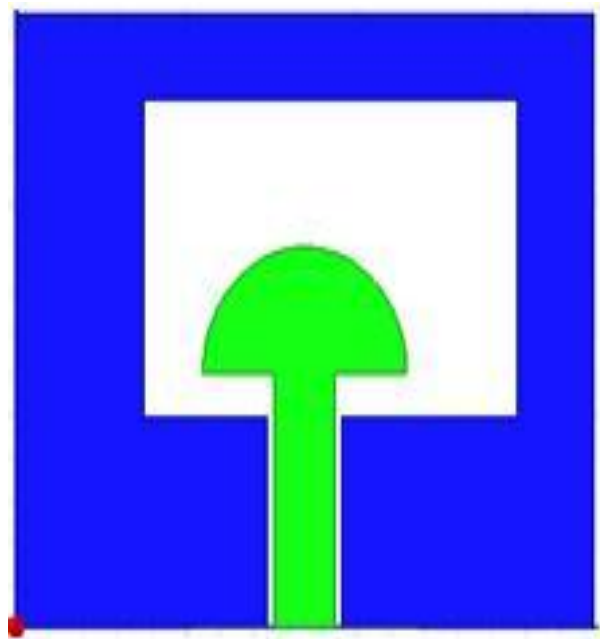

Figure 6. Modified CPW-Fed Rectangular slot antenna Design-II

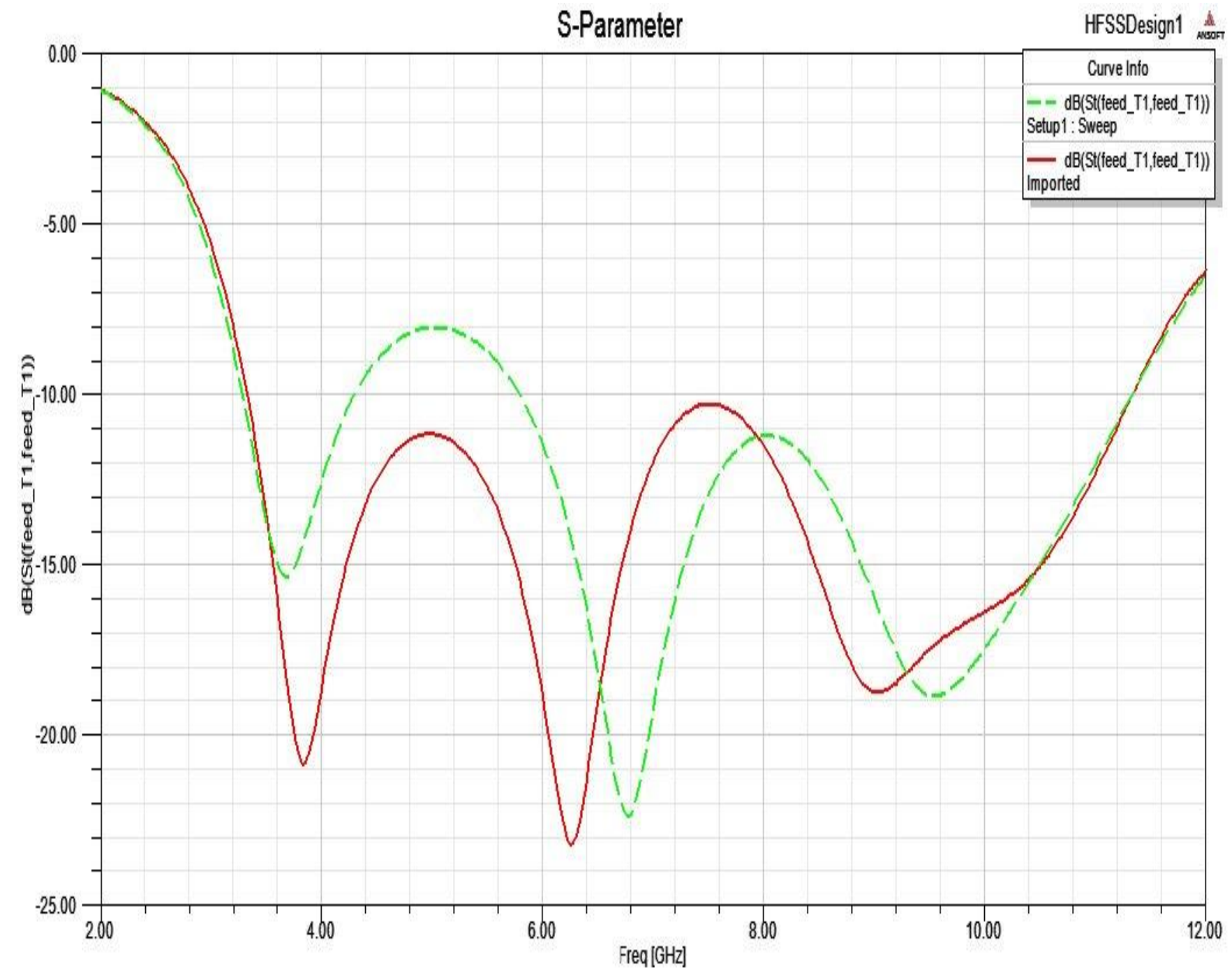

Figure 7. Simulated VSWR of Modified CPW-Fed Rectangular slot antenna Design-II

\subsection{Radiation Pattern}

The simulated radiation pattern of E-Plane and H-Plane are obtained at $3.7 \mathrm{GHz}, 6.7 \mathrm{GHz}$ and $9.7 \mathrm{GHz}$ as shown in fig 8 . It is noticed that in E-Plane the radiation pattern is bidirectional. As the frequency increases, the gain of the antenna increases 

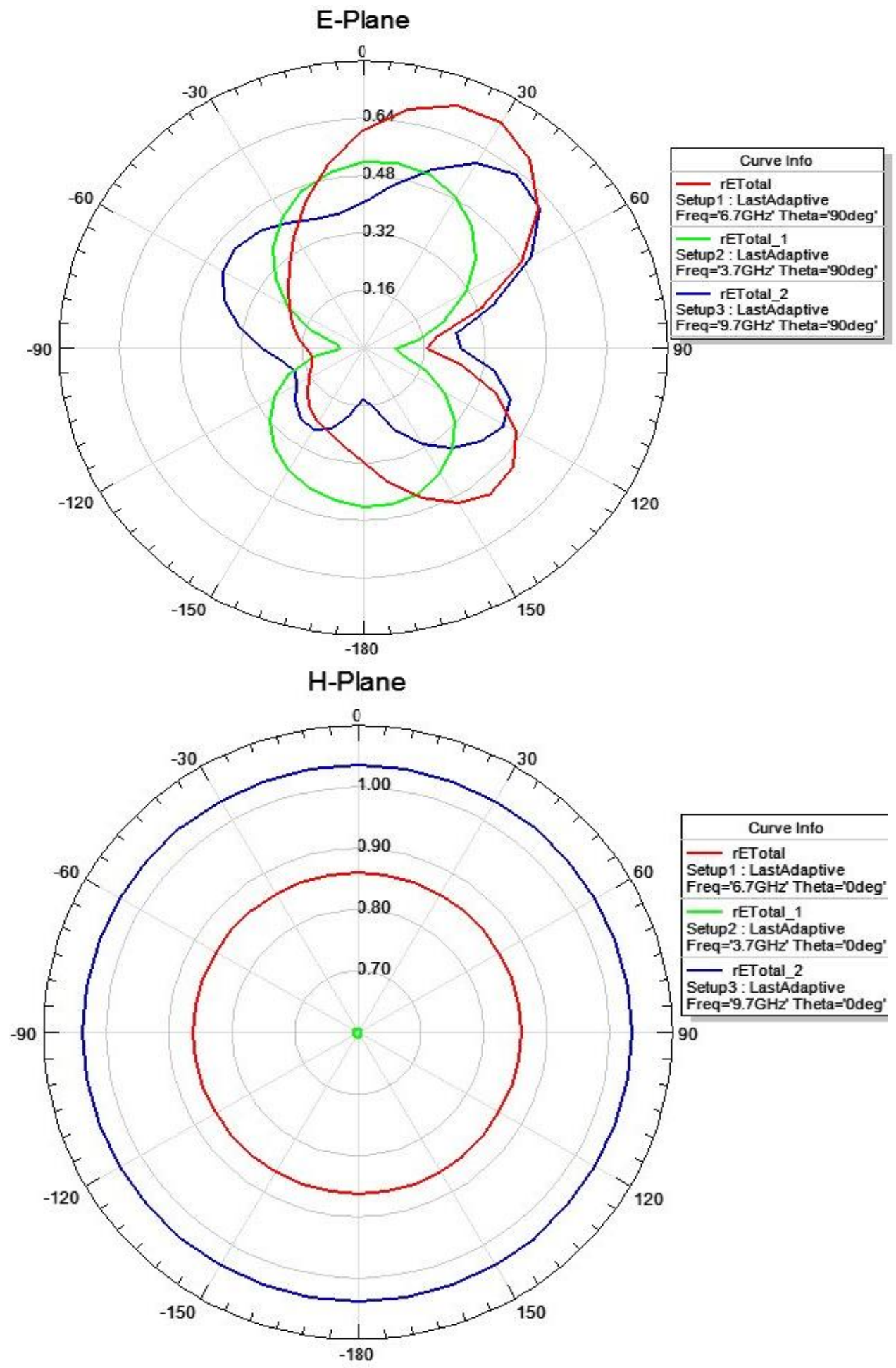

Figure 8. Radiation pattern of Modified CPW-Fed Rectangular slot antenna Design-II at 3.7 GHz, 6.7GHz and 9.7 GHz a) E-Plane (yz-plane) b) H-Plane (xz-plane)

\section{CONCLUSION}

Thus by observing the output of both design we can conclude that the design of slot antenna with modified semi-circular tuning stub gives complete utilization of Ultra wide band frequency range $(3.1 \mathrm{GHz}-10.6 \mathrm{GHz})$. On the other hand the design of slot antenna with semi-circular tuning stub gives 96.93\% utilization of Ultra wide band frequency range $(3.33 \mathrm{GHz}-10.6 \mathrm{GHz})$. In this paper we discussed the two designs of printed slot antenna with their respective size and shapes with creating two vertical slots. When it is to be considered for the UWB applications and the low profile shape, the antenna with Triangular tuning stub promises small size configuration $(21 \mathrm{~mm} * 20 \mathrm{~mm} * 1.6 \mathrm{~mm})$ as compare to the antenna with Semicircular tuning stub $(29 \mathrm{~mm} * 34 \mathrm{~mm} * 1.5 \mathrm{~mm})$. The results included in this report are based on simulations by using HFSS software, for 
validating results antenna fabrication \& measurement of various performances parameter can be done. In future optimization can be carried out to enhance the antenna performance by adjusting various parameters of antenna like slot width \& feed position etc.

\section{ACKNOWLEDGEMENTS}

The author is thankful to the HOD of Electronics \& Communication Department of Sushila Devi Bansal College of Technology for constant encouragement and providing valuable research facilities.

\section{REFERENCES}

[1] First Report and order, Revision of part 15 of the commission's Rule Regarding Ultra-Wideband Transmission System FCC 02-48,Federal Communications Commission, 2002.

[2] Shi Cheng, Paul H., and Anders Rydberg, Prnted Slot Planar Inverted Cone Antenna for Ultrawideband Applications,IEEE Antennas Wireless Propag. Lett., vol. 7, pp. 18-21, 2008.

[3] X. Chen, W. Zhang, R.Ma, J.Zhang and J. Gao, Ultrawideband CPW-fed Antenna with Round Corner Rectangular Slot and Partial Circular Patch, IET Microw.Antennas Propag., vol. 4, pp. 847-851, 2007.

[4] Jin-Ping Zhang, Yun-Sheng $\mathrm{Xu}$, and WeiDong Wang, Microstrip-Fed Semi-Elliptical Dipole Antennas for Ultrawideband Communication, IEEE Trans. Antennas Propag., vol. 56, no. 1, pp. 241-244, Jan. 2008.

[5] P.Li, J. Liang and X. Chen, Study of Printed Elliptical/Circular Slot Antennas for Ultrwideband
Applications, IEEE Trans. Antennas Propag., vol. 54, no. 6, pp. 1670-1675, June 2006.

[6] J. William and R. Nakkeeran. Development of CPW-fed UWB Printed Slot Antenna. National Conference on Communications, Channai, INDIA, 2010.

[7] Pratap N. Shinde, B. K. Mishra, Design of Triple Band Slot Antenna for $802.11 \mathrm{a} / \mathrm{b}$ WLAN and Upper UWB Application Using Pentagon Tuning Stub, International Journal of Microwave And Optical Technology, Vol., No.1, January2013.

[8] Z. Li, C.-X. Zhang, G.-M. Wang, and W.-R. Su Designs On Cpw-Fed Aperture Antenna For Ultra-Wideband Applications,Progress In Electromagnetics Research C, Vol. 2, 1-6, 2008.

[9] K. Nithisopa, J. Nakasuwan, N. Songthanapitak, N. Anantrasirichai and T. Wakabayashi. Design CPW-fed Slot Antenna for Wideband Applications. PIERS ONLINE, Vol. 3, No. 7, pp. 1124-1127, 2007.

[10] John L. Volakis. Antenna Engineering Handbook $4^{\text {th }}$ Edition. The McGraw-Hill, 2007.

[11] C. A. Balanis. Antenna Theory, Analysis \& Design. Jown Wiley \& Sons Inc, New York, 1997.

[12] Slot Antenna. http://www.wikipedia.org/wiki/article:slotantenna

[13] Ansoft HFSS Version 13.0 , Ansys Inc.Canansburg, PA, USA, 2010 